\title{
A JUVENTUDE NOS CAMINHOS DA AÇÃO PÚBLICA
}

\author{
LiLIA Belluzzo
}

Rita de Cássia Victorino

\begin{abstract}
Resumo: Este artigo aborda o tratamento dado aos jovens pelas ações públicas, utilizando a experiência de avaliação do Programa Jovem Cidadão do Governo do Estado de São Paulo, desenvolvida pela Fundação Seade. Ressalta a importância da trajetória da constituição dos direitos civis e os limites decorrentes de práticas sociais de segregação da pobreza no encaminhamento das demandas da juventude.

Palavras-chave: juventude; ação pública; vulnerabilidade social.
\end{abstract}

\begin{abstract}
This article deals with the influence of public actions on youth through the experience of evaluating the Citizen Youth Program of the State of São Paulo's government, developed by Fundação Seade. It emphasizes the influence of the process of the constitution of civil rights and the limits arisen from social practices of poverty segregation on the course of youth's demands. Key words: youth; public action; social vulnerability.
\end{abstract}

É dever da família, da sociedade e do Estado assegurar à criança e ao adolescente, com absoluta prioridade, o direito à vida, à saúde, à alimentação, à educação, ao lazer, à profissionalização, à cultura, à dignidade, ao respeito, à liberdade e à convivência familiar e comunitária, além de colocá-los a salvo de toda forma de negligência, discriminação, exploração, violência, crueldade e opressão.

Constituição Federal

$\mathrm{A}$ s políticas públicas caracterizam-se por processos decisórios voltados para a formulação, implementação e avaliação de ações ou programas destinados ao atendimento das demandas sociais. Essas decisões revelam "o que fazer" ou "não fazer" e, sobretudo, "como fazer”, ou seja, a orientação política que deverá nortear a ação pública e regular as formas de interação entre agentes promotores, parceiros e segmentos-alvo da política.

A ação pública na área social, além da dimensão da prestação de serviços e geração de bens à coletividade, contém a definição dos modos de interação entre os agen- tes da política e sua regulação. Tal ação reflete a concepção do sujeito-alvo e a forma de se lidar com ele, sendo, no plano mais amplo, respaldada pelo modelo políticoinstitucional vigente no país.

Historicamente, as intervenções públicas no Brasil voltadas à área social pouco falam dos - e aos - sujeitos aos quais se destinam. Esses permanecem na posição de beneficiários, esperando a contemplação com serviços ou bens que lhes são reservados e, por conseqüência, pouca ou nenhuma expressão lhes é conferida. As políticas destinadas aos jovens ${ }^{1}$ não fugiram a esse padrão, sendo marcadas por ações que oscilaram entre o controle e a assistência social. Esse padrão revela a baixa permeabilidade social às noções de respeito à cidadania, sobretudo no tocante aos direitos desse segmento.

Somente a partir da segunda metade do século XX inicia-se o processo de ampliação da noção de beneficiário para a de cidadão. No entanto, esses avanços não foram lineares, mas lançaram as bases às conquistas verificadas no final do século. 
Este artigo ressalta, por um lado, a importância da trajetória da constituição dos direitos civis na configuração das temáticas da juventude e, por outro, os limites decorrentes de práticas sociais de segregação da pobreza no encaminhamento das demandas desse segmento. Está organizado em três partes, de forma que a primeira recupera historicamente a introdução da temática da juventude entre as ações do Estado, a qual expressava-se, exclusivamente, no tratamento das questões relativas à infância e à adolescência. Oferecer, assim, um panorama dos temas abordados, das orientações políticas e da posição ocupada pelos segmentos-alvo nos processos de formulação e implementação dessas ações. A segunda parte recupera o contexto social das duas últimas décadas, focalizando o quadro de carências e vulnerabilidade social de parcelas dos jovens metropolitanos e os desafios que se colocavam. A terceira parte visa, por um lado, identificar como agentes e parceiros de programas públicos compreendem os sujeitos-alvo das ações e, por outro, investigar eventuais diferenças no comportamento desses sujeitos, diante dos limites e oportunidades trazidos pelas ações públicas. Para tanto, a análise volta-se ao segmento jovem da população metropolitana de São Paulo atendida pelo Programa Jovem Cidadão - PJC: Meu Primeiro Trabalho, do Governo do Estado de São Paulo, valendo-se da (re)leitura dos resultados das pesquisas realizadas pela Fundação $\mathrm{Seade}^{2}$ com o objetivo de avaliar o programa.

\section{A AÇÃO INSTITUCIONAL E OS JOVENS: ASPECTOS HISTÓRICOS}

A origem das ações públicas no Brasil destinadas à criança e ao adolescente data da segunda metade do século XIX e esteve voltada ao atendimento de crianças órfãs.

Quando São Paulo e Rio de Janeiro eram vilas, os filhos ilegítimos, em maioria mestiços, então denominados "mulatinhos", eram assistidos, em alguma instância, pela comunidade. ${ }^{3}$ Porém, a expansão das cidades, dada pelo crescimento vegetativo da população, pela vinda dos imigrantes europeus e de ex-escravos oriundos do meio rural, ao lado da permanência de comportamentos sociais rígidos que discriminavam os filhos ilegítimos, contribuía para o crescimento do número de crianças "órfãs", culminando na necessidade de criação de mecanismos sociais mais eficientes para assisti-las.

As primeiras ações tiveram por inspiração mecanismos utilizados na Europa de então, denominados "roda dos enjeitados" ou "roda dos expostos", ${ }^{4}$ contavam com a participação da Igreja, eram apoiadas pelo Estado e executadas por Santas Casas de Misericórdia e orfanatos.

A criança que ingressava nessas instituições era tratada juridicamente como órfã, devendo ali permanecer até atingir a maioridade, tal qual definida pela legislação vigente. ${ }^{5}$ No entanto, para parcela dessas crianças, cuja paternidade fora identificada previamente, havia a possibilidade de posterior resgate por algum parente que assim o desejasse, mediante ressarcimento ao Estado, conforme determinação jurídica expressa pelo capítulo $1^{\circ}$ do Decreto de 1854:

Quando os pais ou parentes de algum asylado o reclamarem, provando que se acham em condições de cuidar de sua educação, o Ministro do Imperio mandará entregálo, si julgar conveniente, sob as condições que parecerem necessarias, inclusive a de ser o Estado indenizado das despezas feitas com o asylado desde o dia da sua entrada até ao da sahida.

A indenização será calculada pelo quociente da despeza geral do asylo dividida pelo numero de asylados.

Assim, o ingresso de crianças em orfanatos ou instituições religiosas se dava originariamente pela simples aceitação social de práticas de abandono, normalmente decorrentes de situações de carência material dos pais ou de "desamparo" da mãe. No entanto, a manutenção dessas crianças em instituições similares constituía processo mais complexo, apoiado por determinações e procedimentos da área médica, por concepções e regulamentações jurídicas e por ações de caráter filantrópico, normalmente assumidas pela Igreja Católica.

Tais práticas refletiam a forma pela qual a sociedade entendia e tratava a infância e adolescência pobre ou abandonada, ou seja, esvaziada de direitos e submetida aos interesses da coletividade. Nesse sentido, o discurso médico voltado às preocupações com a saúde pública permitiu a concepção da vacinação como obrigação do indivíduo e não como direito, refletindo a prevalência de práticas destinadas a responder especialmente ao conjunto da sociedade, sugerindo ser o direito à saúde individual dessas crianças questão menor, senão inexistente.

As contribuições da área médica se estendiam e subsidiavam decisões quanto à definição dos beneficiários das ações previstas. Por meio de diagnósticos médicos identificavam-se as crianças portadoras de deficiências ou incapacidades físicas ou mentais para futuro exercício de ofício. Essas crianças deixavam de ser consideradas alvo 
das ações de assistência, que se destinavam somente àquelas aptas para o mundo do trabalho, como atesta o artigo $6^{\circ}$ do Decreto Imperial de 17 de março de 1883:

Não serão, porém, admitidos os que sofrerem de moléstias contagiosas, e os que tiverem defeitos physicos, que os impossibilitem para os estudos e para o aprendizado de artes e officios.

Em síntese, à Justiça cabia definir quais crianças eram órfãs, à Medicina, analisar e diagnosticar as condições físicas das crianças, declarando-as aptas ou não para futuro ingresso no mundo do trabalho. A Igreja era responsável por formá-las moral e intelectualmente e o Estado, por custear todo o processo de formação. Definia-se assim o conjunto de regras que regulamentavam o acesso e a permanência nas instituições de assistência à infância desamparada, colocando em ação objetivos que se mostravam menos permeáveis aos ideais de recuperação e formação integral dessas crianças do que à realização de valores destinados à manutenção do convívio social.

Os direitos reservados às crianças e aos adolescentes permaneciam restritos e estigmatizados, como bem exemplifica a exclusividade no acesso às denominadas Companhias de Aprendizes Menores dos Arsenaes de Guerra, ${ }^{6}$ destinadas aos segmentos em situação de vulnerabilidade social. Segundo artigo $3^{\circ}$ :

\footnotetext{
Só podem ser admitidos nas mesmas Companhias:

$1^{\circ}$ Os expostos.

$2^{\circ}$ Os órfãos indigentes.

$3^{\circ}$ Os menores, que viverem abandonados sem superior, que vale na sua educação.

$4^{\circ}$ Os filhos de pais, que, por sua pobreza, não tiverem meios de os alimentar e educar.
}

As crianças que ingressavam nas Companhias tinham garantia de morada, sustento, vestuário, tratamento médico e educação. Entretanto, obviamente, viviam sob rotinas rígidas, sob inúmeras imposições disciplinares com medidas corretivas no caso de transgressão dos regulamentos internos.

Assim, o tratamento público destinado à criança esteve marcado, em sua origem, pela atenção aos segmentos da infância órfã e pobre, visando assisti-los, mas principalmente afastá-los de uma vida de "vadiagem", 7 integrandoos aos ideais do mundo do trabalho. Essa preocupação aumentou com o crescimento das cidades e de seus problemas sociais, no início do século XX. A sociedade se via diante da ameaça representada pela permanência de grupos de menores que começavam a perambular pelas ruas das cidades. A opinião pública reforçava o mal-estar em torno do fenômeno em questão, contribuindo para que este fosse considerado um problema ou demanda social.

Se na origem a demanda na infância fora definida como necessidade de asilo, diante do abandono paterno e/ou materno, nesse momento o problema se transforma, exigindo que as soluções até então conhecidas fossem repensadas. Os argumentos oscilavam entre dilatar a tutela do Estado sobre os menores, aumentar a assistência social ou intensificar a repressão.

Resultou desse processo a noção da necessidade de uma legislação especial para crianças e adolescentes, sob a "tutela oficial" do Estado e a ampliação do papel da Justiça, tanto como protagonista na formulação do problema quanto como agente responsável pela elaboração e aplicação de medidas basicamente penais, destinadas às crianças e adolescentes abandonados ou em situação de delinqüência, vistos com mais clareza como agentes potenciais de ações criminosas. ${ }^{8}$ Tratava-se da prevalência da abordagem repressiva em detrimento do amparo e reconhecimento dos direitos infanto-juvenis.

À questão da infância e adolescência desamparadas, acrescentavam-se o ingresso precoce no mundo do trabalho fabril, ampliando a dimensão dos problemas verificados no início do século XX. O aumento da pobreza entre as famílias residentes nos centros urbanos contribuía para esse fenômeno. Crianças e adolescentes eram submetidos a condições precárias de trabalho, expostos a situações de insalubridade, a jornadas noturnas e excessivas, além dos acidentes de trabalho. ${ }^{9}$ A despeito da gravidade do quadro e das manifestações de entidades vinculadas às organizações trabalhistas, não houve ações sistemáticas por parte do Estado visando regular ou limitar o ingresso desse segmento social no mercado de trabalho.

Pode-se dizer que os problemas reconfiguravam-se, perversamente influenciados por questões sociais profundas e complexas, mas sobretudo amargavam a ausência do reconhecimento de crianças e adolescentes como sujeitos de direito.

Com a entrada do governo Vargas, nos anos 30, verificaram-se algumas alterações no tratamento de crianças pobres, muito mais por influência da orientação assistencial assumida pelo Estado do que por avanços na compreensão das especificidades dessas questões. De qualquer modo, a situação de carência infanto-juvenil passa a ser tratada de forma integrada ao quadro de pobreza da família. Assim, à abordagem predominantemente jurídica e de 
controle social acrescentava-se a assistencial, voltada ao amparo à maternidade, à infância e à adolescência.

Se até os anos 30 a abordagem predominante - ou mesmo exclusiva - voltava-se à infância e à adolescência, na década de 40 , os jovens passam a ser objeto de atenção, como resultado das exigências do mercado quanto à formação e qualificação da força de trabalho. Pela primeira vez, o Estado apoiava ações destinadas à formação dos segmentos jovens para o trabalho técnico, ainda que mantivesse intervenções destinadas ao controle e amparo de parcelas dessa população. Assim, ao lado de instituições destinadas à tutela de menores abandonados e/ou infratores e de promoção de assistência e amparo, representadas pelo Serviço de Assistência ao Menor - SAM ${ }^{10}$ (1940) e pela Legião Brasileira de Assistência - LBA (1942), foram criados o Serviço Nacional de Aprendizagem Industrial - Senai (1942), o Serviço Social da Indústria - Sesi e o Serviço Nacional de Aprendizado Comercial - Senac, em 1946.

De forma concomitante às novas ações públicas empreendidas, chegava ao país, em 1948 (dois anos após sua criação), o Fundo das Nações Unidas para a Infância Unicef, contribuindo para reforçar a urgência de se instituir patamar próprio às questões da juventude. ${ }^{11}$

Num plano mais amplo, novos paradigmas e contribuições eram trazidos por influência do cenário do pós-guerra às questões da infância e adolescência. Os efeitos perversos da Segunda Grande Guerra trouxeram ao mundo novas exigências, impondo ao contexto internacional a urgência do resgate e da valorização dos direitos humanos e sociais, então brutalmente combalidos pela guerra. O papel de instituições internacionais na luta pelo resgate desses direitos, sobretudo para os segmentos jovens, mostrou-se decisivo, destacando-se as ações da Organização das Nações Unidas - ONU e da Organização dos Estados Americanos - OEA. ${ }^{12}$

As proposições em voga no cenário internacional exerceram sua parcela de influência nas discussões internas. Na passagem da década de 40 para a de 50 , registravamse divergências entre juristas quanto à própria concepção de "menor". Para alguns, tomado como objeto de direito penal, para outros, como sujeito de direito. Duas abordagens diversas expressavam essa dicotomia, uma tratando o problema social dos jovens apenas juridicamente, a partir da formulação e aplicação de legislação penal e medidas repressivas, e outra buscando na sociedade o compromisso com a proteção à infância. Desse contexto resultou a elaboração de projeto de lei federal ${ }^{13}$ reconhecendo os direitos especiais dos menores e descrevendo os direitos indispensáveis à sua "dignidade e ao livre desenvolvimento de sua personalidade", bem como buscando o comprometimento da sociedade com o problema da infância marginalizada.

A questão conquistava novo patamar, pertinente ao campo dos direitos formais específicos a esse ciclo de vida, trazendo a oportunidade de revisão do papel atribuído aos segmentos jovens.

No entanto, o cenário político repressivo imposto pelo golpe de 1964 interrompeu esse processo. Com a emergência do regime autoritário, os problemas sociais perderam sua dimensão política, foram esvaziados de seus conteúdos associados ao campo dos direitos e as demandas sociais, quando expressas publicamente, eram tratadas exclusivamente como casos de polícia. Nesse contexto, as políticas públicas para a infância e adolescência foram reestruturadas, atendendo ao objetivo expresso de implantarem-se nacionalmente como ações de controle e repressão de menores. A criação da Fundação Nacional do BemEstar do Menor - Funabem, ${ }^{14}$ em 1964, em substituição ao SAM (então, conhecido como "escola do crime"), seguiu essa orientação.

Apesar da resistência de diversos setores da sociedade, a passagem da década de 60 para a de 70 caracterizou-se pelo endurecimento do regime militar, pela violação dos direitos civis e humanos e pela suspensão dos direitos políticos, medidas apoiadas, principalmente, no Ato Institucional no 5 (AI-5), de 13 de dezembro de 1968.

Mas o uso da força militar encontrava algum limite nos resultados das eleições de 1974 para o Congresso Nacional, que garantiram, de forma surpreendente, a vitória da oposição, representada pelo Movimento Democrático Brasileiro - MDB, sobre o partido oficial, Aliança Renovadora Nacional - Arena. Esta, no processo eleitoral, teve sua imagem associada às arbitrariedades do governo e às elites sociais do país. A eleição, finalmente, expressava a insatisfação da sociedade com o regime instituído e reforçava o caminho da oposição pela via institucional. O peso da reprovação apressou o planejado processo da "liberalização controlada" ou da "distensão lenta e gradual" trazido pelo governo Geisel, em substituição ao segmento militar então conhecido como "linha dura".

A segunda metade da década de 70 caracterizou-se por avanços e recuos no processo de liberalização do regime e pela permanente resistência por parte de setores da sociedade civil ${ }^{15}$ e da oposição, no Congresso, na luta pelo restabelecimento do Estado de Direito, com o 
fim das medidas de exceção, e pela anistia ampla, geral e irrestrita. A revogação do Ato Institucional $\mathrm{n}^{\circ} 5$ e o retorno do pluralismo partidário, em 1979, representaram marcos decisivos ao processo de liberalização do regime político.

Nesse contexto, os problemas da infância e adolescência voltam a conquistar expressão pública, tornando-se objeto de pressões que resultaram em ações de caráter diverso daquelas propostas pelo regime vigente, com destaque para a instalação da Comissão Parlamentar de Inquérito - CPI do Menor, em 1976, e a criação da Pastoral do Menor, em 1978. Essas ações encontravam respaldo em proposições de organismos internacionais, como as Nações Unidas. Esta elegeu 1979 como Ano Internacional da Criança ${ }^{16}$ reforçando a urgência de resposta adequada às demandas específicas da infância e chamando a sociedade e o Estado a cumprirem suas responsabilidades diante das questões identificadas. ${ }^{17}$ Assim, politizou-se a discussão voltada aos problemas dos segmentos menos favorecidos socialmente.

$\mathrm{O}$ processo de liberalização do regime e a posterior passagem do poder a um presidente civil possibilitaram a instalação, em 1987, do Congresso Constituinte e a promulgação da Constituição da União, em outubro de 1988. O texto constitucional refletia a necessidade de alteração do quadro social no país, reconhecendo na conquista dos plenos direitos da cidadania um valor. Nesse sentido, podese dizer que a nova Constituição:

ampliou o escopo dos direitos sociais, modificou o perfil das relações trabalhistas no país e definiu um novo padrão descentralizado de intervenção pública na área social, envolvendo importantes alterações na estrutura tributária nas atribuições e responsabilidades do Estado (UNICAMP/ NEPP, 1989, p. 17).

Em conformidade à Constituição de 1988 e às diretrizes internacionais nas quais a criança e o adolescente figuram como sujeitos de direito, foi aprovado, em 1990, o Estatuto da Criança e do Adolescente - ECA, marcando o compromisso da sociedade brasileira em promover mudanças destinadas à valorização dos direitos e à realização das potencialidades da criança e do adolescente, além de fornecer garantias de proteção a esses segmentos.

A promulgação do ECA materializou a expectativa de segmentos sociais organizados de que se garantissem aos jovens, além dos direitos básicos à cidadania, direitos específicos associados ao reconhecimento das necessidades de seu ciclo vital. Segundo o artigo $3^{\circ}$ :
A criança e o adolescente gozam de todos os direitos fundamentais inerentes à pessoa humana, sem prejuizo da proteção integral de que trata esta Lei, assegurando-se-lhes, por lei ou por outros meios, todas as oportunidades e facilidades, a fim de lhes facultar o desenvolvimento físico, mental, moral, espiritual e social, em condições de liberdade e de dignidade.

Nessa direção, o ECA pretende contribuir para o tratamento de problemas que historicamente restringem e punem a infância e a adolescência, tais como o trabalho infantil, a violência doméstica, a exploração sexual e a utilização de medidas apenas punitivas no tratamento da infração juvenil. Para tanto, prevê a instituição de mecanismos descentralizados que possibilitem ampliar o controle social sobre os programas públicos e a adoção de medidas socioeducativas aos adolescentes infratores, em lugar das punitivas.

Trata-se, de um lado, dos conselhos estaduais e municipais, compostos por representantes da sociedade e do poder público, em paridade, com competência para formular diretrizes de ação e fiscalizar programas sociais, e de outro lado, dos conselhos tutelares, compostos por representantes da comunidade e do judiciário e destinados à aplicação das medidas judiciais.

No entanto, a ausência desses conselhos em cerca de mil municípios brasileiros demonstra a dificuldade de implantação dos mesmos. ${ }^{18}$ Embora um variado conjunto de razões contribua para esse quadro, destacam-se a interferência excessiva dos prefeitos, seja nas indicações de representantes para a composição dos conselhos seja no funcionamento dos mesmos, e a resistência de membros do judiciário em trabalhar em parceria com a sociedade civil, no caso exclusivo dos Conselhos Tutelares.

As conquistas formais representaram a possibilidade de novo tratamento às demandas de crianças e adolescentes, de sua valorização como sujeitos, rompendo com a tradição histórica de tutela sobre esse segmento. A despeito de tais conquistas, o Brasil vive o dilema de possuir, por um lado, um arcabouço legal de garantias e, por outro, a permanência de situações e comportamentos sociais que negligenciam ou ferem os direitos da infância e adolescência. ${ }^{19}$

Mas as dificuldades enfrentadas por segmentos infantojuvenis ultrapassam a não-realização dos direitos formais e têm no aprofundamento das carências sociais na década de 80 e na ampliação do desemprego, sobretudo juvenil, nos anos 90 , catalisadores do quadro de vulnerabilidades sociais. 


\section{A VULNERABILIDADE SOCIAL DOS JOVENS METROPOLITANOS}

A retomada da democracia política e, mais especificamente, a ampliação da participação dos movimentos sociais reivindicatórios, sobretudo na condição de interlocutores que atuam no encaminhamento e na negociação de demandas sociais, contribuíram para o reconhecimento da dimensão política do quadro social de pobreza. Surgiu, assim, a oportunidade para que parcelas dos segmentos empobrecidos viessem a conquistar seu papel de sujeito.

No entanto, a ampliação e manutenção do quadro de carências sociais entre amplos setores da população, sobretudo nas duas últimas décadas, colaboraram para a vigência de interpretações e formas de atuação social conservadoras, que se expressam, segundo Lúcio Kowarick, em duas "matrizes de atuação diversas, mas articuladas entre si". A primeira, designada matriz de controle e acomodação social pela naturalização dos acontecimentos, considera que a pobreza é socialmente tratada como "inelutavelmente natural". Essa matriz não haveria como escapar das leis do mercado, da globalização, do avanço tecnológico ou da hierarquização social, imprimindo componente de desobrigação diante da tarefa de solucionar os impasses da pobreza, considerada como "natural", e as relações sociais quase aceitas como excludentes. ${ }^{20} \mathrm{~A}$ essa matriz acrescenta-se a matriz de controle e acomodação social pela neutralização, a qual está baseada em mecanismos de persuasão, constrangimento e coação destinados a reforçar relações desiguais que perpetuam a subalternidade de segmentos da sociedade e reforçam a existência de um espaço social reservado exclusivamente aos pobres, por meio de práticas ou atitudes que marginalizam a pobreza, roubando do pobre sua condição de sujeito (KOWARICK, 2003, p. 19).

Assim, pode-se dizer que com a pobreza são gerados socialmente os referenciais e moldadas as práticas de "integração" social desses pobres. Sem dúvida, essas práticas não passam desapercebidas, sobretudo entre parcelas dos jovens. A existência de grupos organizados de adolescentes, na periferia das grandes cidades, ${ }^{21}$ gerando uma cultura própria, expressa principalmente por meio da música, da dança, da maneira de falar, de se vestir e se comportar vem sendo interpretada como forma de resistência aos processos de "desfiliação" social em curso. O exercício da resistência parece se apoiar, nesses casos, no fato de o jovem pertencer a um grupo social com o qual se identifica e de experimentar o sentimento de valorização de sua condição social e de sua juventude. Mas a impermeabilidade da maioria das esferas da sociedade a esses grupos é indiscutível, "recolocando" parcelas deles na condição de indivíduos pobres e subalternos.

O processo histórico de identificação das demandas sociais, não raramente, tem levado a opinião pública a proceder à equivocada transferência do problema ao público-alvo das ações, rotulando e estigmatizando os segmentos atendidos, dando expressão a noções que integram as clássicas matrizes de controle e acomodação social abordadas anteriormente. Nesse contexto, o papel das políticas públicas, seja na formulação dos problemas, seja na implementação das ações, parece ser bastante significativo.

O desafio é reorientar as politicas de juventude na direção de um modelo de jovens cidadãos e sujeitos de direito, que deixe paulatinamente para trás enfoques como o do jovemproblema que ameaça a segurança pública. E isso requer um esforço a mais no plano simbólico (BANGO, 2003, p. 50).

Enquanto a noção da relevância do papel dos sujeitosalvo para o aprimoramento das políticas sociais ganha espaço na literatura especializada, o mesmo parece não acontecer no processo das políticas públicas. Os programas sociais, desde sua formulação, não chegam a conceber seus beneficiários como sujeitos da ação, embora, por vezes, incluam entre os objetivos propostos o resgate da cidadania.

As metas destinadas à promoção da cidadania, quando de fato contempladas pelas políticas públicas, costumam ocorrer dentro dos limites da implantação dos programas. Apesar de restrita, essa prática constitui oportunidade de imprimir mudanças na maneira de lidar com as populações-alvo das ações governamentais e de conceber o papel das políticas sociais, aproximando-o de noções segundo as quais:

As politicas sociais não podem limitar-se exclusivamente a uma dimensão de prestação de serviços. Devem incluir, ainda, a promoção da participação dos atores sociais, de modo que [...] se mobilizem e se adaptem não somente às necessidades, mas também a seus projetos vitais (BANGO, 2003, p. 50).

No entanto, a inflexão na forma de conceber o sujeito da política exige algum grau de superação da racionalidade puramente instrumental, que costuma nortear as ações públicas e que se caracteriza por visar soluções imediatas 
a problemas formulados a partir da constatação de "sintomas que causam mal-estar social". Trata-se de construir outra racionalidade, que tenha, no sujeito atendido, a contrapartida da ação, prevendo mecanismos para sua participação no processo em curso e formulando indicadores capazes de apurar os resultados dessa participação, tanto para a população quanto para o desempenho do programa.

Nessa direção, a literatura especializada chama a atenção para a necessidade de a ação pública com viés social ter como premissa o conhecimento prévio dos jovens-alvo da política implantada. Isso não ocorre sem razão, uma vez que avaliações de programas públicos destinados ao segmento jovem ou mesmo pesquisas primárias junto a parcelas dessa população apontam as influências de fatores sociais no comportamento do jovem e em sua capacidade de responder a estímulos e de aproveitar oportunidades geradas por programas governamentais.

A relevância dos diagnósticos sociais como subsídios à formulação e implementação de programas públicos é confirmada pelos resultados obtidos a partir da metodologia do Índice de Vulnerabilidade Juvenil - IVJ (FUNDAÇÃO SEADE, 2002). A partir do IVJ, observa-se que a desigualdade social na Região Metropolitana de São Paulo se expressa de diferentes maneiras, mas sobretudo de acordo com o local de moradia desses jovens, componente fundamental na definição do acesso a serviços e a equipamentos sociais. Assim, revelar o "endereço" do jovem é expor sua condição social, confirmando a elevada associação entre local de residência e presença de carências sociais.

Dentre os resultados da metodologia do IVJ, destacase a maior ocorrência de baixos rendimentos nos distritos da periferia do município de São Paulo. O rendimento mensal auferido pelos chefes de domicílios em alguns distritos localizados, principalmente, nos extremos das zonas sul e leste, e em menor proporção na zona norte, ${ }^{22}$ não ultrapassou o valor nominal de $\mathrm{R} \$ 700,,^{23}$ sendo, portanto, bastante inferior aos R $\$ 1.500$ registrados no conjunto da capital paulista. Além dos baixos rendimentos, nesses distritos registraram-se ocorrência elevada de homicídio de jovens, maior presença de adolescentes com filhos e proporções elevadas de jovens com ensino fundamental incompleto, configurando quadro de extrema vulnerabilidade social.

Ao expressivo conjunto de carências sociais desses jovens, acrescenta-se a dificuldade de ingresso no mercado de trabalho. Dados da Região Metropolitana de São
Paulo, com crescentes taxas de desemprego, sobretudo nos anos 90, confirmam esse quadro. Segundo informações da Pesquisa de Emprego e Desemprego - PED (Fundação Seade/Dieese), em janeiro de 1994, o desemprego entre pessoas de 15 a 17 anos era de $37,8 \%$, tendo passado para $53,6 \%$, em janeiro de 2004. Em igual período de referência, a taxa de desemprego para a população de 18 a 24 anos passou de $19,1 \%$ para $28,8 \%$.

Aos jovens coloca-se o desafio de ingressar num mercado restrito e exigente quanto ao perfil de sua força de trabalho. De acordo com essa perspectiva, faltariam a esses jovens experiência profissional e formação educacional, particularidades perfeitamente compreensíveis tendo-se em vista o ciclo de vida em que se encontram esses sujeitos.

A resposta governamental a essa situação tem se dado por meio de políticas de valorização da formação educacional básica, por um lado, e por programas destinados a promover as primeiras experiências no mundo do trabalho, por outro lado.

No entanto, os investimentos na educação básica, indiscutivelmente de grande importância, não têm se mostrado suficientes diante da atual dinâmica do mercado de trabalho. Houve, ao longo da década de 90 , considerável ampliação dos níveis de escolaridade entre os jovens metropolitanos. A freqüência ao ensino médio e sua conclusão confirmam o alcance das ações na área educacional destinadas à recuperação do desempenho escolar, sobretudo no nível fundamental, tradicionalmente uma barreira. Segundo dados da Pesquisa de Condições de Vida PCV, da Fundação Seade, em 1994, 37,7\% dos jovens entre 15 e 17 anos freqüentavam o ensino médio, já em 1998, 51,5\% estavam nessa condição. Também o segmento entre 18 e 24 anos experimentou aumento de escolaridade: 29,6\% havia concluído o nível médio em 1994, e, em 1998, a proporção subiu para $37,6 \%$.

Com o intuito de responder ao descompasso entre aquisição de escolaridade e oportunidades no mundo do trabalho, diferentes experiências governamentais vêm sendo empreendidas por meio de programas destinados a contribuir para o futuro ingresso dos segmentos jovens no mercado de trabalho. Nessa direção destacaram-se, nos anos 90, os programas: Capacitação Solidária (Associação de Apoio ao Programa Capacitação Solidária e parceiros); Primeiro Emprego (governo estadual do Rio Grande do Sul); Serviço Civil Voluntário (governo federal, Estados e parceiros); Bolsa Trabalho (prefeitura de São Paulo); finalmente, Jovem Cidadão: Meu Primeiro Trabalho (governo estadual de São Paulo). 
Com o intuito de investigar o papel reservado ao jovem no âmbito da ação governamental, este artigo destaca alguns resultados do Programa Jovem Cidadão - PJC: Meu Primeiro Trabalho, ${ }^{24}$ implantado em maio de 2000 e acompanhado pela Fundação Seade.

O projeto de avaliação teve por base os objetivos do PJC e contou com metodologia elaborada integralmente pela Fundação Seade. As informações foram coletadas a partir de pesquisas quantitativas primárias com inscritos no programa em diferentes situações (estagiários, egressos e não-selecionados para estágio ${ }^{25}$ e com empresas parceiras; de entrevistas semi-estruturadas com parcelas dos jovens, dos agentes do programa, dos responsáveis pelo PJC nas empresas e nas escolas parceiras; por fim, de grupos de discussão com egressos do programa. Acrescenta-se, ainda, a utilização periódica das informações que integram a base de dados gerenciais do programa. ${ }^{26}$ Do conjunto dessas informações resultou variada produção analítica voltada à apuração: do desempenho do programa quanto às variações de oferta, demanda e atendimento; do perfil social dos jovens, de suas expectativas e benefícios decorrentes do programa; das expectativas das empresas em relação ao programa; e das dificuldades na implementação do programa.

\section{A JUVENTUDE NO PROGRAMA JOVEM CIDADÃO: MEU PRIMEIRO TRABALHO}

Tomando por referência as matrizes de controle e acomodação social, destacadas por Lúcio Kowarick, prossegue-se com a (re)leitura de resultados obtidos pelo projeto de avaliação do Programa Jovem Cidadão - PJC. Tais dados apontam a ocorrência de atitudes entre parceiros do programa que perpetuam a desigualdade nas relações sociais e marginalizam a pobreza, contribuindo para que os jovens socialmente carentes se sintam em situação de inferioridade e impossibilidade diante das oportunidades geradas pelo PJC. Essa análise baseia-se, principalmente, em informações qualitativas resultantes de depoimentos tomados de jovens inscritos, de agentes e parceiros do programa e focaliza, sobretudo, o processo seletivo nas empresas parceiras, mecanismo pelo qual o jovem inscrito no PJC tem acesso ao estágio.

Dentro do variado conjunto de resultados da avaliação do Programa Jovem Cidadão, destacam-se os relativos ao perfil social dos atendidos, os quais apontam a existência de heterogeneidade social, refletindo, portanto, a realidade juvenil no município de São Paulo.
Parcelas dos jovens que participam do PJC provêm de distritos socialmente privilegiado ${ }^{27} \mathrm{e}$, geralmente, aproveitam bem a experiência de estágio. Ainda que, segundo depoimentos coletados, ocorram situações de recusa por parte do jovem às vagas que lhes são ofertadas, ora por considerarem o valor da bolsa-estágio insuficiente, ${ }^{28}$ ora por não se interessarem pelo perfil da vaga ofertada. De modo geral, os jovens oriundos desses distritos são identificados pelos dirigentes escolares entrevistados como bons alunos, com boa capacidade de expressão, com pouco problema de auto-estima e capazes, desde que assim o queiram, de aproveitar muito bem as oportunidades geradas pelo programa.

Já os jovens das regiões mais carentes apresentam, segundo os dirigentes entrevistados, baixa auto-estima, o que por vezes os impede de se inscrever no programa ou os coloca em situação de grande insegurança e desvantagem quando submetidos ao processo seletivo para estágio.

Depoimentos obtidos junto a representantes das escolas que participam do PJC reforçam essa análise, revelando que as unidades escolares localizadas em bairros de extrema carência social são vistas com desconfiança pelas empresas parceiras, prejudicando o desempenho dos jovens que as freqüentam nos processos seletivos. São escolas que recebem alunos extremamente carentes, que, segundo agentes do programa, são freqüentemente reprovados nos processos seletivos para vagas de estágio, em parte pelo estigma social que pesa sobre a escola e o bairro de onde provêm, em parte por assumirem comportamento de excessiva timidez e passividade diante de seus entrevistadores, dominados pela ansiedade de obter um estágio e pela dúvida quanto ao próprio potencial, acentuada, provavelmente, por uma baixa auto-estima. A coordenadora de uma das escolas parceiras revela em sua fala certa naturalidade na forma de conceber a pobreza, similar à matriz de controle e acomodação social pautada na noção da naturalização dos acontecimentos ou da inevitabilidade da pobreza. Destaca-se em seu depoimento a seguinte observação:

Para o aluno mais carente vai sempre existir uma lacuna, ele vai mal aqui, a auto-estima dele já é muito baixa, ai ele não é requisitado [para a vaga de estágio], não pode provar nada, nunca (FUNDAÇÃO SEADE/SERT, dez. 2002, p. 15).

Na percepção de um dos agentes do programa que atua na orientação dos jovens pré-selecionados, encaminhando-os para entrevistas nas empresas, esses estudantes foram assim definidos: 
Você começa a conversar com eles [os jovens candidatos às vagas] e sente que estão muito inibidos. Muitos jovens ficam sozinhos em casa, não há convívio familiar, a gente observa muito isso na periferia. [...] estão muito perdidos mesmo [...] tem aluno que não consegue receber aquilo que você está passando (FUNDAÇÃO SEADE/SERT, nov. 2002, p. 16).

Nessa direção caminhou também o depoimento da representante de uma das empresas parceiras:

no processo de entrevista, eles [jovens] se sentem extremamente impotentes e pequenos, sem valor, principalmente, quando vêm de uma situação carente (FUNDAÇÃO SEADE/ SERT, abr. 2002, p. 8).

O diretor pedagógico de uma escola localizada na periferia do município de Mogi das Cruzes também revela em seu testemunho atitudes de forte discriminação da pobreza, similares à noção de neutralização da pobreza:

[...] há certa rejeição [por parte das empresas à escola onde o entrevistado trabalha], [...] quando o aluno vai para a entrevista, perguntam de que escola ele é, e dependendo da escola... tem esse preconceito, infelizmente. Eles discriminam as escolas deste bairro aqui, por ser um bairro carente. [...] O sobrinho da dirigente [dessa escola] disse que isso é verdade, ele comentou que a pessoa [de uma empresa parceira] que o entrevistou [para uma vaga pelo PJC], quando perguntou de qual escola ele vinha, falou: "Nossa! Essa escola só tem bandido" (FUNDAÇÃO SEADE/SERT, dez. 2002, p. 8). ${ }^{29}$

De forma emblemática, a noção de neutralização $d a$ pobreza aparece em trecho de depoimento de um representante de empresa, que aborda a definição dos critérios de seleção de seus estagiários. Segundo o entrevistado:

outro critério importante [de seleção para estágio] é a origem dos candidatos: prefiro que eles morem na região [o entrevistado referia-se a uma das regiões próximas ao centro da capital] [...] há uma diferença muito grande entre os alunos do Alberto Levy - escola que funciona na Av. Indianópolis e de onde vêm atualmente alguns estagiários - e os do Embu. As pessoas do Embu se comunicavam supermal, não sabiam falar. Você percebia que eles não tinham o mínimo, enquanto outros, de uma região mais civilizada, menos afastada, você já vê que a pronúncia é outra, a pessoa aprende com mais facilidade (FUNDAÇÃO SEADE/ SERT, abr. 2002, p. 9).

Esses depoimentos ganham em gravidade seja pela relação desigual entre o elevado número de jovens inscritos no programa e a baixa quantidade de vagas ofertadas nas regiões socialmente carentes, ${ }^{30}$ seja pelo acesso socialmente desigual a essas vagas. Os resultados da pesquisa quantitativa realizada no segundo semestre de 2003, com os egressos de estágio e com os jovens recusados no processo seletivo, confirmam a associação entre condição social do jovem e possibilidade de acesso ao estágio. ${ }^{31}$ Enquanto cerca de um terço dos egressos pesquisados vinha de famílias com rendimentos de até R \$ 500 mensais, entre os não-aprovados essa proporção subia para 45,4\%, sendo ainda maior para os jovens residentes na região sul da $\operatorname{RMSP}(54,7 \%)$ e nos municípios do $\mathrm{ABC}(56,3 \%)$. Em contrapartida, quase $20 \%$ dos egressos de estágio tinham rendimento familiar superior a $\mathrm{R} \$ 1.100$, e na região central (da capital) essa proporção alcançava 27,4\%; já entre os jovens recusados para estágio, apenas 9,9\% provinha de famílias com esse perfil de rendimento (FUNDAÇÃO SEADE/SERT, 2004, p. 13).

Esses resultados sugerem, uma vez mais, duas formas de discriminação social da pobreza que se reforçam pela renda e pelo local de residência. Vale lembrar que a declaração dos rendimentos familiares não faz parte do processo seletivo, normalmente realizado por meio de entrevista, o que vem confirmar a existência de outras formas de se reconhecer (e punir) a pobreza. É evidente que há um conjunto de justificativas, reais ou não, para efetuar a recusa desses jovens, sendo que em proporção elevada de casos, eles mesmos consideram-se responsáveis pela própria recusa, por estarem nervosos demais $(41,1 \%)$ ou por se considerarem pouco preparados para a entrevista (30,5\%), conforme dados de 2004 (FUNDAÇÃO SEADE/ SERT, 2004, p. 33).

Na direção semelhante, identificam-se, entre os jovens pesquisados, relatos que atribuíram a sua reprovação à falta de capacitação adequada às expectativas da empresa. ${ }^{32}$ Esses argumentos podem refletir realidade ou, simplesmente, encobrir outras razões para essa recusa, já que ao lado dessas justificativas houve outras, que na perspectiva dos jovens constituíram formas de mascarar preconceitos sociais e de cor, expressos pelas restrições à aparência física do candidato em $15 \%$ dos casos pesquisados.

As dificuldades expressas pelos depoimentos acima ganham a conotação de "desperdício" de oportunidades quando se ouve da própria clientela que passou pela experiência de estágio avaliações muito positivas quanto às conquistas pessoais após a passagem pelo programa:

o jovem sai daquela inércia, ele sai das ruas, aquele jovem que de repente estava em casa, assistindo àqueles telejornais, 
sem esperança nenhuma, vendo o tempo passar, não conseguindo emprego nenhum, ele vai e consegue emprego, sai daquelas companhias que ele poderia estar encontrando na rua, drogas, porque a cabeça vazia é oficina do diabo (FUNDAÇÃO SEADE/SERT, jun. 2002, p. 27).

Os ganhos se fazem sentir também na forma pela qual o jovem passa a ver o relacionamento com sua família. Segundo depoimento de um ex-estagiário, as mudanças ocorrem:

[...] porque ele [o jovem] acaba vendo como ele trata as pessoas no serviço, e passa a pensar como vai tratar os pais em casa, ele começa a repensar tudo, e isto é inconscientemente, nem é conscientemente (FUNDAÇÃO SEADE/SERT, jun. 2002, p. 26).

Os depoimentos de parcelas desses jovens dividiramse entre avaliações positivas e negativas do programa, mas em geral revelaram a oportunidade de aprendizado pessoal proporcionado pela experiência, mesmo quando essa fugia às expectativas iniciais. Isso foi traduzido da seguinte maneira por um dos entrevistados:

Não é só a cabeça que muda, você fica totalmente diferente, nos seus estudos você se esforça mais, em tudo o que você vai fazer, em tudo, [...] você se empenha mais, faz mesmo. Os desafios mais dificeis que vinham, acho que eu estou enfrentando porque deu mais força, estou enfrentando com mais força. [...] tirei lições de responsabilidade e força de vontade, porque se você quer alguma coisa na vida você tem que correr atrás [...] aprendi a ser mais flexível, ter espirito de equipe, ser responsável, ter autoconfiança. Eu percebi também que não era a área que eu queria trabalhar (FUNDAÇÃO SEADE/SERT, jun. 2002, p. 35).

Os depoimentos dos jovens sugerem que o aprendizado obtido por meio da experiência de estágio contribui em diferentes direções, alterando antigas noções, atitudes e comportamentos, expressando ganhos de maturidade, influenciando projetos de vida, relacionamentos pessoais e sociais e, por todas essas razões, fortalecendo nesses jovens percepções quanto a seus potenciais de aprendizado, nem tanto técnicos, tampouco profissionais, mas de formação integral para a vida em sociedade.

Se os ganhos relatados são meritórios à formação desses jovens, em compensação, as reprovações no processo de seleção para o estágio constituem forte impacto para um público cuja identidade ainda está em construção, como ilustra depoimento de uma jovem selecionada para entrevista e recusada por diversas vezes: "eu ficava nervosa e eu cheguei a chorar em várias vezes porque eu fazia a entrevista e nada, ninguém me ligou. E nada, nada, não adianta você entrar em depressão, eu sou nova ainda. Sou nova, mas a maioria dos meus amigos conseguiu, por quê eu não? Eu devo ter alguma coisa de errada para eles não me pegarem." (Depoimento de um jovem demandante).

A avaliação do programa e, sobretudo, as justificativas e atitudes no processo seletivo dos estudantes inscritos no PJC identificadas nos depoimentos obtidos mostram-se similares às concepções que fundamentam as matrizes da naturalização dos acontecimentos e da neutralização.

A despeito dos objetivos exclusivamente sociais, as oportunidades geradas pelo PJC são limitadas por práticas correntes na sociedade que contribuem para a segregação da pobreza, reservando aos jovens socialmente carentes acesso restrito até mesmo aos benefícios gerados pela ação pública. Nesse sentido, a discriminação social da pobreza explícita e naturalmente aceita no século XIX nas ações direcionadas às crianças e aos adolescentes encontra limites na conquista e efetivação dos direitos civis amplos e específicos dos segmentos juvenis. No entanto, tal conquista parece manter-se ainda subordinada à condição social do jovem, em que situações de pobreza e vulnerabilidade social prosseguem restringindo a efetivação de seus direitos e adiando, uma vez mais, a oportunidade de esses segmentos exercerem plenamente seu papel de sujeito, independentemente de gênero, cor e, sobretudo, de renda familiar.

\section{NOTAS}

Este artigo apóia-se no resultado do trabalho coletivo dos funcionários da Fundação Seade e em especial dos técnicos da Divisão de Estudos Especiais. As autoras agradecem em particular a Sônia Nahas de Carvalho, pela leitura de versão preliminar e pelas sugestões apresentadas.

1. Há significativas diferenças na definição dos conceitos de infância, adolescência e juventude. Este artigo considera os segmentos jovens, sob perspectiva histórica a partir das ações públicas, não se prendendo à definição prévia de recortes etários.

2. O projeto de Avaliação do Programa Jovem Cidadão: Meu Primeiro Trabalho permaneceu sob a responsabilidade da Fundação Seade entre outubro de 2000, data de início do programa, e dezembro de 2003.

3. Utilizando-se do mecanismo de compadrio, maneira informal de assistir às crianças das famílias pobres e de instituir uma co-responsabilidade (moral e financeira) na criação destas, os genitores, homens brancos ricos, apadrinhavam seus filhos ilegítimos, furtando-se, dessa maneira, do reconhecimento legal dessa paternidade. Esse mecanismo era efetivado no seio da Igreja e até incentivado por ela, como forma de absorver socialmente essa criança. 
4. Sistema criado no século XVII na França, em que recém-nascidos eram abandonados pelos pais para que fossem criados por alguma família ou instituição. A criança era colocada em uma "roda" existente na porta de muitos orfanatos e Santas Casas de Misericórdia, em seguida girava-se a roda de forma a deixar a criança no interior da instituição. Neste caso, o anonimato dos pais era resguardado. Destaca-se que o índice de mortalidade infantil nesses estabelecimentos oscilava entre $50 \%$ e $70 \%$. Durante os séculos XVII, XVIII e XIX, na Europa, receberam-se 42.200 enjeitados dessa maneira.

5. Conforme artigos $3^{\circ}, 4^{\circ}$ e $5^{\circ}$ do Decreto Imperial de 17 de março de 1883: "São considerados desvalidos os meninos de nacionalidade brazileira, que não tiverem pessoa alguma que os deva e possa manter e dar-lhes conveniente educação. Serão admitidos no Asylo: $1^{\circ}$ Os que forem orphãos de pai e mãi; $2^{\circ}$ Os que forem orphãos de pai; $3^{\circ}$ Os que, com pai e mãi, não puderem ser por elles mantidos ou educados. As condições de admissão serão provadas; sendo orphão o menor, com attestados de completa indigencia e de absoluta falta de amparo, passados pelo Vigario da freguezia em que residir o dito menor e pelo Juiz respectivo, e com certidões de idade e de obito dos pais, ou documentos equivalentes a essas certidões; não sendo orphão e menor, por analogos attestados pelo Vigario e Subdelegado da respectiva freguesia”.

6. Trata-se de companhias destinadas à formação militar dos jovens carentes, mantidas pelo Estado, sob responsabilidade da Secretaria de Estado dos Negócios da Guerra, regulamentadas por Lei Federal n. 243, de 30 de novembro de 1841 .

7. A noção de que esses jovens seriam facilmente cooptados pelos adultos que viviam em situação de vadiagem era corrente nas instâncias jurídica e policial e se expressava também pela imprensa.

8. Datam desse período a criação do Juizado de Menores, em 1923, e do Código de Menores, em 1927.

9. Em março de 1917 foi criado o Comitê Popular de Agitação Contra a Exploração de Menores nas Fábricas, em decorrência do expressivo número de ocorrências de ferimentos, mutilações e mortes de crianças nas fábricas.

10. O SAM foi extinto em 1964, em virtude de uma série de rebeliões dos internos. Ainda assim, pode-se dizer que seu formato e sua concepção inspiraram a constituição da Febem.

11. O Fundo das Nações Unidas para a Infância - Unicef foi criado em 11/12/1946, durante a primeira sessão da Assembléia Geral das Nações Unidas. Os primeiros programas do Unicef forneceram assistência emergencial a milhões de crianças no período pós-guerra (na Europa, no Oriente Médio e na China). Em 1950, o Unicef teve seu mandato ampliado para atender as crianças de todo o mundo em desenvolvimento e, em 1953, tornou-se órgão permanente do sistema das Nações Unidas.

12. A OEA muito contribui para a valorização dos direitos da criança e do adolescente, sobretudo por meio da promoção dos Congressos PanAmericanos da Criança. Mesma direção verifica-se com a instalação da Assembléia Geral das Nações Unidas, que aprovou, em 1959, a Declaração Universal dos Direitos da Criança.

13. Projeto n. 1.000-56, denominado "Novo Código".

\section{Lei Federal n. 4.513 de 01/12/1964.}

15. Destacavam-se os movimentos estudantis e sindicais, as associações profissionais, sobretudo a OAB, a Igreja Católica, além de partidos e organizações políticas.

16. As Nações Unidas, desde 1959, elegem a cada ano um tema, com objetivo de chamar a atenção da opinião pública internacional para os grandes problemas sociais.

17. As questões identificadas referiam-se principalmente à violência policial contra crianças e adolescentes, à ação de grupos organizados de extermínio de jovens supostamente infratores e a ausência de direitos básicos, sobretudo na área da saúde.
18. Segundo divulgação do Ministério da Justiça, em 1.383 municípios brasileiros nenhum dos conselhos previstos existe. Disponível em: $<$ http://www.mj.gov.br>. Acesso em: 26/03/04.

19. Pode-se citar como exemplo de desrespeito ao ECA o massacre da Candelária (em que oito crianças "de rua" foram mortas por policiais militares no Rio de Janeiro) ou mesmo os dados dos organismos oficiais como o IBGE, segundo os quais em 2000, 7,5 milhões de crianças entre 10 e 17 anos trabalhavam, sendo que 3,3 milhões com menos de 14 anos. Desse total, 1,9 milhão não recebera remuneração pelo seu trabalho. Das crianças remuneradas, $88,8 \%$ ganhavam até um salário mínimo, com carga horária média de 26,5 horas semanais (IBGE/PNAD, 2001).

20. A referida noção, segundo Kowarick (2003), decorre de uma matriz de atuação clássica que "pode ser designada de controle e acomodação social pela naturalização dos acontecimentos. [...] Trata-se de discursos da imponderabilidade [...] ou da inevitabilidade daquilo que é assim porque assim sempre foi".

21. Os grupos, em geral, são de expressão artística predominantemente de rap (Racionais MCs, Sistema Negro Judiciário - SNJ), hip-hop, grafite e capoeira.

22. Esses distritos são: Marsilac, Jardim Ângela, Grajaú, Parelheiros, Pedreira, São Rafael, Iguatemi, Cidade Tiradentes, Itaim Paulista, Jardim Helena, Lajeado, Guaianases, Vila Curuçá, Vila Jacuí, Perus, Anhangüera e Brasilândia.

23. Os dados de rendimento considerados pela metodologia do IVJ tiveram como fonte o Censo Demográfico de 2000.

24. O programa tem por objetivo proporcionar aos jovens que freqüentam a rede pública de ensino da RMSP sua primeira experiência no mundo do trabalho, por meio de estágio remunerado, realizado preferencialmente em empresas privadas. Constitui uma parceria entre governo do Estado de São Paulo e iniciativa privada, visando disponibilizar vagas de estágio pelo período de seis meses aos jovens de 16 a 21 anos que freqüentam a segunda ou terceira séries do ensino médio. Para tanto, os jovens inscrevem-se em suas próprias escolas e aguardam a oportunidade de participar de processo seletivo nas empresas que ofertam estágio.

25. Foram realizadas quatro pesquisas quantitativas, abrangendo cerca de 7 mil jovens inscritos e pré-selecionados pelo programa.

26. A elaboração e manutenção dessa base de dados é de responsabilidade da Prodesp.

27. São os distritos do centro, centro-sul e centro-oeste do município de São Paulo, definidos pela Secretaria Estadual da Educação.

28. O valor da bolsa definido pelo programa é de R $\$ 130$ mensais.

29. Esse depoimento encontra referência na noção de "discriminação por endereço" que, segundo Novaes, constitui um dos principais critérios de seleção dos jovens pelo mercado de trabalho. Para a autora, há regiões da metrópole que trazem consigo mais do que um indicador de renda, de pertencimento de classe, traz o estigma das áreas urbanas subjugadas pela violência. Assim, algumas justificativas explicam a recusa na contratação de jovens de determinadas regiões da cidade, segundo depoimentos de empregadores: "o jovem que mora em tal lugar de bandidos é um bandido em potencial: melhor não empregar [...] mora ali, ele não vai poder sair pra trabalhar quando houver um conflito entre grupos de traficantes ou entre os traficantes e a polícia: melhor não empregar" (NOVAES, 2003). E, por fim, o medo de que esse jovem possa "vir a cometer alguma falta contra o patrão ou a empresa, seja por solidariedade [...], seja por medo [ser coagido a colaborar com bandidos]. Então: 'melhor não arriscar"” (NOVAES, 2003).

30. Ressalta-se que a maior dificuldade enfrentada pelo programa vem sendo a disparidade entre a expressiva demanda por estágios e a limitação na geração das vagas. Tal como formulado, o PJC depende da adesão das empresas ao programa e de sua disponibilidade em gerar vagas para estágio. Além da significativa pressão da demanda, a geração de vagas de estágio é regionalmente desigual, as regiões centrais 
contam com maior volume de vagas, enquanto as franjas das regiões leste e sul e, em menor medida, norte, com números bem mais modestos. Em novembro de 2003, o conjunto da região leste contava com 235 candidatos por vaga, na região sul, 328 candidatos por vaga; na norte, 524 candidatos por vaga; enquanto no centro da capital, essa relação era de 29 candidatos por vaga (FUNDAÇÃO SEADE/SERT, 2003, p. 5).

31. Entre os egressos, foram pesquisados 607 jovens e, entre os nãoaprovados, 406 jovens, representando, no primeiro caso, $77 \%$ do total de egressos do programa e, no segundo, $40 \%$ do total dos não-aprovados. Em ambos os casos foram considerados apenas os jovens que se inscreveram no programa no período entre agosto de 2002 e janeiro de 2003.

32. Entre as justificativas dadas pelo contratante, a partir da perspectiva do jovem recusado, destacaram-se: a falta de conhecimento em informática e deficiências em redação, interpretação de textos e expressão oral.

\section{REFERÊNCIAS BIBLIOGRÁFICAS}

BANGO, J. Políticas de juventude na América Latina: identificação de desafios. In: FREITAS, M.V.; PAPA, F. de C. (Org.). Políticas Públicas: juventude em pauta. São Paulo: Cortez, 2003.

CARVALHO, S.N. Avaliação de Programas Sociais: Balanço das experiências e contribuições para o debate. São Paulo em Perspectiva, São Paulo, Fundação Seade, v. 17, n. 3-4, p. 185-197, jul./ dez. 2003.

CONSTITUIÇÃO FEDERAL. Capítulo VII - Da família, da criança, do adolescente e do idoso. Artigo 227.

FAUSTO, B. Crime, Cotidiano e Poder. São Paulo: Brasiliense, 1985.

FREITAS, M.V.; PAPA, F. de C. (Org.). Políticas Públicas: juventude em pauta. São Paulo: Cortez, 2003.

FUNDAÇÃO SEADE. Metodologia - Índice de Vulnerabilidade Juvenil - IVJ. São Paulo: maio 2002.

Vinte anos no ano 2000: estudos sociodemográficos sobre a juventude paulista. São Paulo: 1998.

FUNDAÇÃO SEADE/SERT. Avaliação do Programa Jovem Cidadão: Meu Primeiro Trabalho. Relatório de análise: Pesquisa com alunos inscritos no período março/agosto 2002. São Paulo: Contrato Seade/Sert, jan. 2004.

. Avaliação do Programa Jovem Cidadão: Meu Primeiro Trabalho. Boletim 4 - out./nov. 2003. São Paulo: Contrato Seade/Sert, dez. 2003.
Avaliação do Programa Jovem Cidadão: Meu Primeiro Trabalho. Relatório de análise II: Pesquisa qualitativa com escolas que aderiram ao PJC. São Paulo: Contrato Seade/Sert, dez. 2002.

. Avaliação do Programa Jovem Cidadão: Meu Primeiro Trabalho. Relatório de análise III: Pesquisa qualitativa com monitores do PJC. São Paulo: Contrato Seade/Sert, nov. 2002.

Avaliação do Programa Jovem Cidadão: Meu Primeiro Trabalho. Relatório VII: Pesquisa qualitativa com ex-estagiários. São Paulo: Contrato Seade/Sert, jun. 2002.

Avaliação do Programa Jovem Cidadão: Meu Primeiro Trabalho. Relatório VI: Pesquisa qualitativa com empresas. São Paulo: Contrato Seade/Sert, abr. 2002.

. Avaliação do Programa Jovem Cidadão: Meu Primeiro Trabalho. Estudo I: Perfil socioeconômico da população estudante de ensino médio. São Paulo: Contrato Seade/Sert, nov. 2000.

IBGE. Pesquisa Nacional por Amostras de Domicílios - PNAD. Rio de Janeiro: 2001.

KOWARICK, L. Sobre a vulnerabilidade socioeconômica e civil: Estados Unidos, França e Brasil. Revista Brasileira de Ciências Sociais, São Paulo, v. 18, n. 51, fev. 2003.

Trabalho e vadiagem: a origem do trabalho livre no Brasil. São Paulo: Brasiliense, 1987.

MADEIRA, F.R. Pobreza, escola e trabalho - convicções virtuosas, conexões viciosas. São Paulo em Perspectiva, São Paulo, Fundação Seade, v. 7, n. 1, p. 70-83, jan./mar. 1993.

NOVAES, R. Juventude, exclusão e inclusão social: aspectos e controvérsias de um debate em curso. In: FREITAS, M.V.; PAPA, F. de C. (Org.). Politicas Públicas: juventude em pauta. São Paulo: Cortez, 2003. p. 121-142.

SKIDMORE, T.E. A lenta via brasileira para a democratização: $1974-$ 1985. In: STEPAN, A. (Org.). Democratizando o Brasil. Rio de Janeiro: Paz e Terra, 1988. p. 27-81.

TELLES, V.S. Sociedade civil e a construção de espaços públicos. In: DAGNINO, E. (Org.). Anos 90 - política e sociedade no Brasil. São Paulo: Brasiliense, 1994. p. 30-45.

UNICAMP/NEPP. Brasil 1987: Relatório sobre a situação social do país. Campinas: 1989 .

Lilia Belluzzo: Socióloga, Analista da Fundação Seade (lbelluzz@seade.gov.br).

Rita de Cássia Victorino: Socióloga, Analista da Fundação Seade (rcvictor@seade.gov.br). 